\title{
Effects of abnormal cannabidiol on oxytocin-induced myometrial contractility
}

\author{
Diarmaid D Houlihan, Michael C Dennedy and John J Morrison \\ Department of Obstetrics and Gynecology, Clinical Sciences Institute, University College Hospital, \\ National University of Ireland Galway, Newcastle Road, Galway, Ireland \\ Correspondence should be addressed to J J Morrison; Email: john.morrison@nuigalway.ie
}

\begin{abstract}
The objective of this study was to investigate the effects of abnormal cannabidiol (abn-cbd) on oxytocin-induced myometrial contractility occurring during pregnancy. Isometric tension recordings were performed in isolated myometrial strips from biopsies obtained at elective cesarean section. The effects of cumulative doses of abn-cbd $\left(10^{-9}-10^{-5} \mathrm{M}\right)$ on oxytocin-induced myometrial contractions alone, and on those following pre-incubation with SR 144528, AM 251, methylene blue, and iberiotoxin were measured, and doseresponse curves were constructed. The $\mathrm{pD}_{2}\left(-\log \mathrm{EC}_{50}\right)$ values and the maximal inhibitory $(\mathrm{MMI})$ values that were achieved were compared for each tissue type. Abn-cbd exerted a potent relaxant effect on oxytocin-induced myometrial contractions in vitro. Pre-incubation with the guanylate cyclase inhibitor, methylene blue, and the $\mathrm{BK}_{\mathrm{Ca}}$ channel antagonist, iberiotoxin, significantly attenuated this effect (for $\mathrm{pD}_{2}, \boldsymbol{P}<0.01$; for $\mathrm{MMI}, \boldsymbol{P}<\mathbf{0 . 0 1}$ ). Abn-cbd exerts a potent inhibitory effect on human uterine contractility. This effect is partially mediated through modulation of guanylate cyclase and activation of $\mathrm{BK}_{\mathrm{Ca}}$ channel activity. These findings have implications for physiologic regulation of myometrial quiescence.

Reproduction (2010) $139783-788$
\end{abstract}

\section{Introduction}

The endocannabinoids comprise a family of eicosanoid and related unsaturated fatty acid derivatives, of which anandamide was the first to be described (Devane et al. 1992). Two cannabinoid receptors that belong to the superfamily of $\mathrm{G}_{\mathrm{i}} / \mathrm{G}_{\mathrm{o}}$ protein-coupled receptors have been cloned (Howlett 2002). The cannabinoid type 1 (CB1) receptor is expressed primarily in the brain and peripheral tissues (Matsuda et al. 1990, Howlett 2002), while the cannabinoid type 2 (CB2) receptor appears to be confined to the cellular components of the immune system (Berdyshev 2000). In addition to the welldescribed neurobehavioral effects of cannabinoids, the endocannabinoids influence important biological and physiological processes (Hillard 2000, Pertwee 2001, Wilson \& Nicoll 2002).

The cannabinoids are known to exert profound relaxant effects on smooth muscle systems. The mechanisms underlying these effects are varied and include alteration of sympathetic nervous tone (Ishac et al. 1996), modulation of vanilloid receptors located on perivascular nerves (Zygmunt et al. 1999), and finally direct interaction with cannabinoid receptors located on smooth muscle cells and on pre-junctional neurons in various mammalian tissues (Gebremedhin et al. 1999, Martin et al. 2000, Hinds et al. 2006). Abnormal cannabidiol (abn-cbd) is a synthetic regioisomer of cannabidiol, which mediates a relaxant effect in isolated rat mesenteric artery via a mechanism that is distinct from CB1 and CB2 receptor activation (Jarai et al. 1999), and is independent of nitric oxide signaling and vanilloid receptor activation (Offertaler et al. 2003). The vascular smooth muscle relaxant effect of abn-cbd occurs via a mechanism that involves guanylate cyclase signaling and potassium channel activation, but a distinct receptor mediating this effect has not been identified yet (Begg et al. 2003).

Endocannabinoids may play an important role in the modulation of parturition and pregnancy (Park et al. 2004). Our group has demonstrated previously that endogenous and exogenous cannabinoids, $\Delta^{9}$-tetrahydrocannabinol and anandamide, mediate a direct, relaxant effect on myometrial contractility in vitro through an action at the CB1 receptor, which is sensitive to blockade by the CB1 receptor antagonist SR 141716, but not to that by the CB2 receptor antagonist SR 144728 (Dennedy et al. 2004). There are no further studies investigating other putative mechanisms of cannabinoidinduced myometrial relaxation. The aims of this study were to investigate the direct effects of the synthetic cannabinoid, abn-cbd, on human uterine contractility during pregnancy, and to investigate non-CB1/non-CB2 mechanisms through which this compound produces myometrial relaxation. 


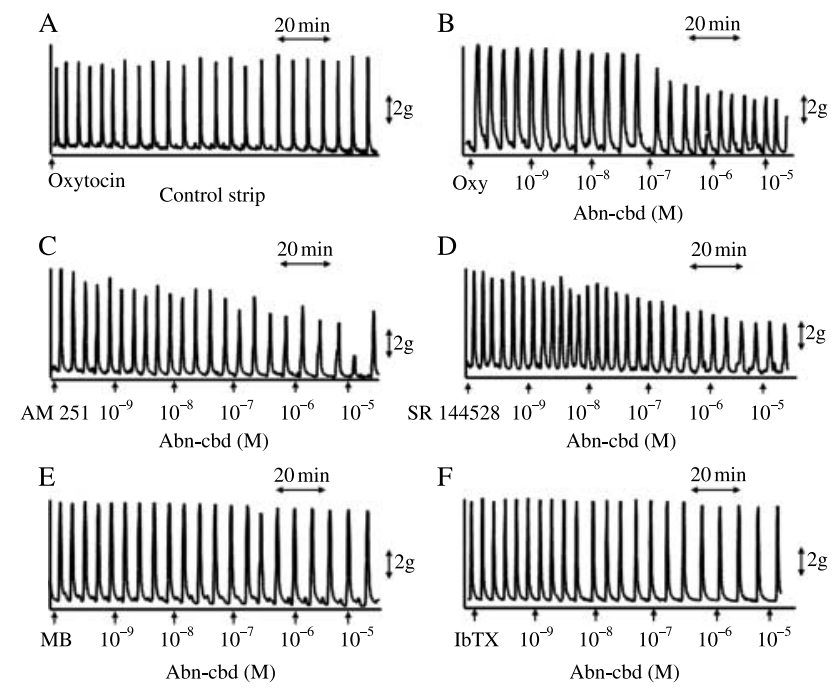

Figure 1 Effects of abn-cbd on myometrial contractions. (A) Representative recordings of oxytocin-induced contractions of pregnant human myometrium. (B) The effects of cumulative additions of abn-cbd $(1 \mathrm{nM}-10 \mu \mathrm{M})$ at 20-min intervals to this tissue type. The myometrial response to incremental doses of abn-cbd following pre-incubation with (C) AM 251, (D) SR 144528, (E) methylene blue (MB), and (F) iberiotoxin (IbTX).

\section{Results}

Abn-cbd exerted a potent concentration-dependent inhibitory effect on oxytocin-induced myometrial contractions in vitro. The calculated $\mathrm{pD}_{2}$ for abn-cbd was $5.81 \pm 0.34$, while the maximal inhibitory (MMI) response value was $60.27 \pm 4.70 \%$. Representative recordings demonstrating the effects of abn-cbd on oxytocin-induced myometrial contractions and the effects of vehicle control on similar strips are shown in Fig. $1 \mathrm{~A}$ and $\mathrm{B}$.

The effects of pre-treatment with the following agents: AM 251 (Fig. 1C), SR 144528 (Fig. 1D), methylene blue (Fig. 1E), and IbTX (Fig. 1F) on uterine contractions, following the addition of cumulative doses of abn-cbd, are demonstrated in Fig. 1. Comparison of $\mathrm{pD}_{2}$ and $\mathrm{MMI}$ values for the relaxant effects of abn-cbd on all myometrial contraction types revealed a significant difference across the groups (for $\mathrm{pD}_{2}, P<0.01$; for $\mathrm{MMI}$, $P<0.01)$. The $\mathrm{MMI}$ value and $\mathrm{pD}_{2}$ value for each respective group are given in Table 1. Pre-incubation with the CB1 antagonist, AM 251, or the CB2 antagonist, SR 144528, did not produce an effect on the doseresponse curve following the sequential addition of abncbd as illustrated in Figs 2 and 3. Post hoc analysis showed that the addition of these compounds did not yield a significant difference in the $\mathrm{pD}_{2}$ or $\mathrm{MMI}$ values across these groups $(n=6$, Table 1$)$.

Conversely, pre-incubation of the tissue baths with both the guanylate cyclase inhibitor, methylene blue, and the selective $\mathrm{BK}_{\mathrm{Ca}}$, channel antagonist, IbTX, produced a parallel rightward shift of the dose-response compared with vehicle controls. Post hoc analysis of these data showed a significant difference between the $\mathrm{pD}_{2}$ and the $\mathrm{MMI}$ values for abn-cbd in the presence and absence of these compounds $(n=6, P<0.01$, Table 1$)$. Figures 4 and 5 illustrate the respective dose-response curves. There were no differences in the contractile activity between control strips and those pre-incubated with each of the test drugs.

\section{Discussion}

Our study demonstrates that the compound abn-cbd exerts a potent inhibitory effect on human uterine contractility in vitro. The magnitude of this inhibition is comparable to that of other established physiological and pharmacological uterorelaxant agents including human chorionic gonadotropin, cyclooxygenase inhibitors, $\beta$-adrenergic agonists, and oxytocin antagonists (Buscher et al. 2001, Dennedy et al. 2001, Slattery et al. 2001, Doheny et al. 2003). Abn-cbd has a potency of myometrial relaxation that is similar to the naturally occurring cannabinoids, anandamide $\left(\mathrm{pD}_{2}\right.$ value $5.58 \pm 0.42$ and $\mathrm{MMI}$ value $75.8 \pm 2.20$ ) and $\Delta^{9}$-tetrahydrocannabinol $\left(\mathrm{pD}_{2}\right.$ value $5.19 \pm 0.91$ and MMI value $75.1 \pm 1.15$; Dennedy et al. 2004). The findings from this study show that signaling via the CB1 or CB2 receptor is not a major component of the abd-cbd-mediated myometrial relaxation. Pre-incubation with methylene blue caused a significant reduction in the inhibitory effect of abn-cbd on myometrial contractility. At tissue bath concentrations used in this study, methylene blue is a selective antagonist of soluble guanylate cyclase and does not influence spontaneous uterine contractile activity (Houlihan et al. 2002,

Table $1 \mathrm{pD}_{2}$ and maximal inhibitory (MMI) values following the sequential addition of cumulative doses of abnormal cannabidiol (abn-cbd) to all tissue types.

\begin{tabular}{|c|c|c|c|c|c|}
\hline Agonist & Antagonist & Site of action & $n$ & $\mathrm{pD}_{2} \pm$ s.E.M. & MMI \pm S.E.M. $\%$ \\
\hline Abn-cbd & None & None & 6 & $5.81 \pm 0.34$ & $60.27 \pm 4.71$ \\
\hline Abn-cbd & AM 251 & CB1 receptor antagonist & 6 & $5.61 \pm 0.46$ & $56.32 \pm 7.40$ \\
\hline Abn-cbd & SR 144528 & CB2 receptor antagonist & 6 & $5.63 \pm 0.33$ & $55.67 \pm 6.72$ \\
\hline Abn-cbd & Methylene blue & Guanylate cyclase inhibitor & 6 & $4.48 \pm 0.17 *$ & $30.40 \pm 3.78^{+}$ \\
\hline Abn-cbd & Iberiotoxin & $\mathrm{BK}_{\mathrm{Ca}}$ channel antagonist & 6 & $4.52 \pm 0.21^{*}$ & $31.17 \pm 4.51^{\dagger}$ \\
\hline
\end{tabular}

${ }^{*} P<0.01$ versus $\mathrm{pD}_{2}$ values for abn-cbd and all other groups. ${ }^{\dagger} P<0.01$ versus maximal inhibition values for abn-cbd and all groups. Analysis of variance followed by Fisher's LSD (protected $t$-test) test. 


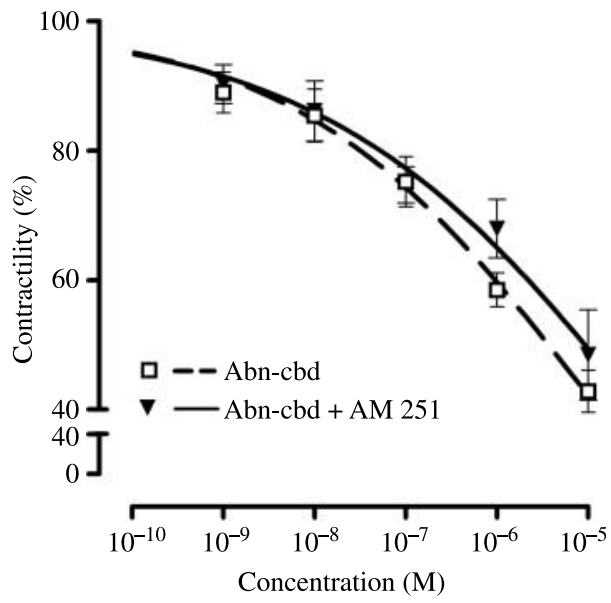

Figure 2 Dose-response curves for abn-cbd in the presence and absence of the selective CB1 receptor antagonist AM 251. Graphical representation of the effects of cumulatively increasing tissue bath concentrations of abn-cbd $(1 \mathrm{nM}-10 \mu \mathrm{M})$ at 20-min intervals on tissue contractility following the addition of oxytocin only (open squares) and following pre-incubation with AM 251 (shaded triangle). Percentage contractility is shown on the $y$-axis and the concentration of abn-cbd is shown on the $x$-axis. The symbols that are used represent the mean values within each group. Vertical error bars represent the S.E.M.

Modzelewska \& Kostrzewska 2005). The addition of IbTX, a potent inhibitor of $\mathrm{BK}_{\mathrm{Ca}}$ channel activity, also significantly attenuated the myometrial relaxant effect produced by the sequential addition of incremental doses of abn-cbd. It is therefore possible that abn-cbd-mediated uterine relaxation is largely effected via cyclic GMP or via $\mathrm{BK}_{\mathrm{Ca}}$ channel activation, and there

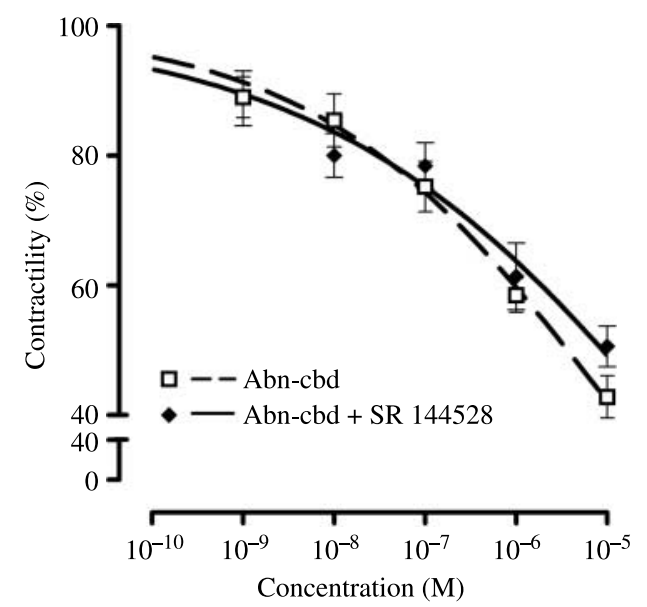

Figure 3 Dose-response curves for abn-cbd in the presence and absence of the selective CB2 receptor antagonist SR 144528. Graphical representation of the effects of cumulatively increasing tissue bath concentrations of abn-cbd $(1 \mathrm{nM}-10 \mu \mathrm{M})$ at 20-min intervals on tissue contractility following the addition of oxytocin only (open squares) and following pre-incubation with SR 144528 (shaded diamond). Percentage contractility is shown on the $y$-axis and the concentration of abn-cbd is shown on the $x$-axis. The symbols that are used represent the mean values within each group. Vertical error bars represent the S.E.M. remains the possibility, not proven in this study, that an alternative or novel cannabinoid receptor may be involved.

The role of the cannabinoids in human pregnancy and parturition remains incompletely understood, and it is the subject of further study. Serial measurement of the endocannabinoid, anandamide, during human pregnancy suggests that serum concentrations of this compound increase during pregnancy with peak concentrations detected just before the onset of labor (Habayeb et al. 2004). CB1 receptor inactivation in mice induces preterm labor by altering normal progesterone and estrogen levels, in addition to interfering with the corticotropin-releasing hormone-corticosterone axis during late pregnancy (Wang et al. 2008). We have demonstrated previously the expression of $\mathrm{CB} 1$ and $\mathrm{CB} 2$ receptors on human pregnant myometrium, and have also shown that endocannabinoids and naturally occurring cannabinoids exert a potent relaxant effect on human pregnant myometrium. This effect is mediated predominantly by the activation of the CB1 receptor, and occurs independently of the CB2 receptor (Dennedy et al. 2004). Myometrial cells are richly endowed with $\mathrm{BK}_{\mathrm{Ca}}$ channels, and endogenous regulation of these channels is thought to play an important role in the maintenance of uterine quiescence during pregnancy (Khan et al. 1997). The cGMP/guanylate cyclase, a second messenger system in human myometrium, is gestationally regulated and directly modulates $\mathrm{BK}_{\mathrm{Ca}}$ channel activity during early pregnancy (Levitan 1994, Zhou et al. 2000).

There are three further points that are to be considered in the interpretation of the findings of this study. First, all tissue specimens for our study were excised from the upper region of the lower uterine segment. As there are no data quantifying or describing the distribution of cannabinoid receptors, atypical or otherwise, in human uterine tissue, it is not possible to conclude that similar sensitivity to abn-cbd would be demonstrated in myometrial biopsy taken from the uterine fundus. There are significant ethical constraints to excising biopsies from the uterine fundus for research purposes. However, there is reasonable evidence indicating that many functional effects and contractile properties of isolated myometrium from the upper and lower segments of pregnant women are similar (Luckas \& Wray 2000). Secondly, our studies were all carried out in myometrial tissue obtained at term. While there is no reason to suspect altered sensitivity to these compounds in preterm myometrial tissue, further studies investigating gestation- or parturition-linked changes in cannabinoid function in human myometrium are required. The primary purpose of this study was to examine the effects of the compound abn-cbd on human myometrial contractions, and the findings have revealed that it exerts a potent relaxant effect, the mechanism of which remains partially explained. 


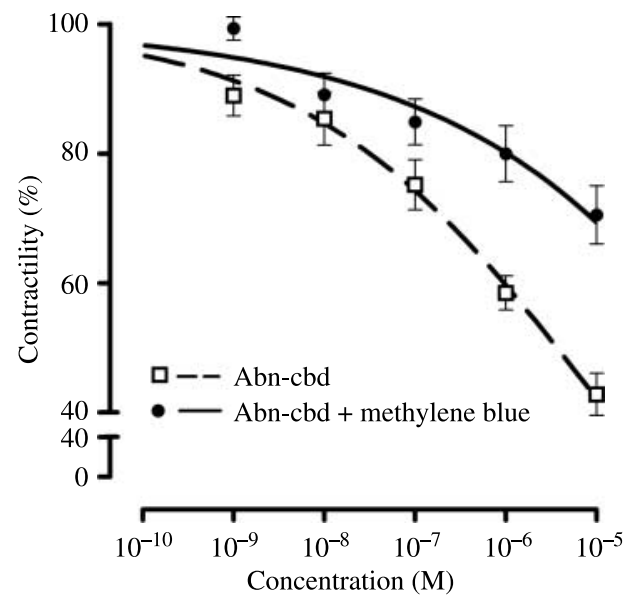

Figure 4 Dose-response curves for abn-cbd in the presence and absence of the selective guanylate cyclase inhibitor methylene blue. Graphical representation of the effects of cumulatively increasing tissue bath concentrations of abn-cbd $(1 \mathrm{nM}-10 \mu \mathrm{M})$ at 20-min intervals on tissue contractility following the addition of oxytocin only (open squares) and following pre-incubation with methylene blue (shaded circle). Percentage contractility is shown on the $y$-axis and the concentration of abn-cbd is shown on the $x$-axis. The symbols that are used represent the mean values within each group. Vertical error bars represent the S.E.M.

\section{Materials and Methods}

\section{Tissue collection}

Women were recruited for the study from those attending the Department of Obstetrics and Gynecology, University College Hospital, Galway, Ireland. Biopsies of human myometrial

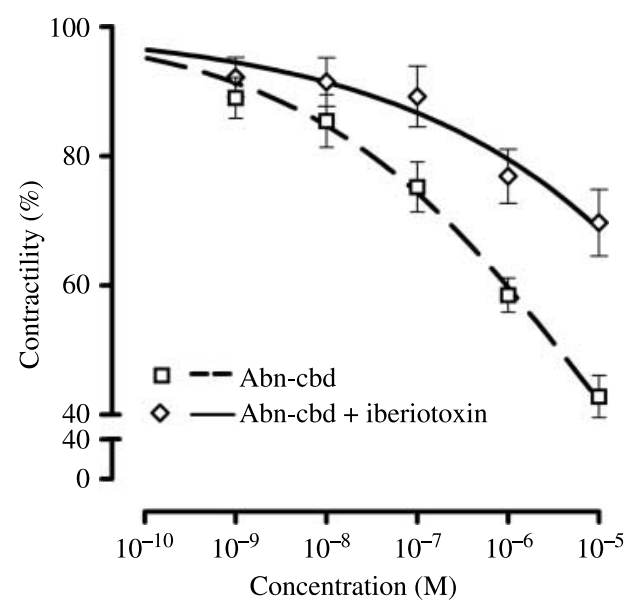

Figure 5 Dose-response curves for abn-cbd in the presence and absence of the selective $\mathrm{BK}_{\mathrm{Ca}}$ channel antagonist iberiotoxin. Graphical representation of the effects of cumulatively increasing tissue bath concentrations of abn-cbd $(1 \mathrm{nM}-10 \mu \mathrm{M})$ at 20-min intervals on tissue contractility following the addition of oxytocin only (open squares) and following pre-incubation with iberiotoxin (open diamonds). Percentage contractility is shown on the $y$-axis and the concentration of abn-cbd is shown on the $x$-axis. The symbols that are used represent the mean values within each group.

Vertical error bars represent the S.E.M. tissue in pregnancy were obtained at elective cesarean section performed at term (mean maternal age 33.4 years, $n=12$ ). The reasons for cesarean section included breech presentation, previous cesarean section, and clinically diagnosed cephalopelvic disproportion. The median parity value of the women at the time of delivery was 2 (range 0-3). All women were given regional anesthesia for cesarean delivery. The biopsies were excised from the midline portion of the upper lip of the incision in the lower uterine segment. Ethical committee approval for the study was obtained from the Research Ethics Committee at University College Hospital, Galway, and recruitment was done by written informed consent. Following collection, the tissue was placed in Krebs-Henseleit physiological salt solution of the following composition: potassium chloride, $4.7 \mathrm{mmol} / \mathrm{l}$; sodium chloride, $118 \mathrm{mmol} / \mathrm{l}$; magnesium sulfate, $1.2 \mathrm{mmol} / \mathrm{l}$; calcium chloride, $1.2 \mathrm{mmol} / \mathrm{l}$; potassium phosphate, $1.2 \mathrm{mmol} / \mathrm{l}$; sodium bicarbonate, $25 \mathrm{mmol} / \mathrm{l}$; and glucose, $11 \mathrm{mmol} / \mathrm{l}$ (Sigma-Aldrich). Tissue was stored at $4{ }^{\circ} \mathrm{C}$ and used within $12 \mathrm{~h}$ of collection.

\section{Tissue bath experiments}

Longitudinal myometrial strips were dissected, measuring $\sim 2 \times 2 \times 10 \mathrm{~mm}$, and mounted under $2 \mathrm{~g}$ of tension in organ tissue baths for isometric recording as described previously (Houlihan et al. 2002). The tissue baths contained $20 \mathrm{ml}$ of Krebs-Henseleit physiological salt solution, which was maintained at $37{ }^{\circ} \mathrm{C}$ and at a $\mathrm{pH}$ of 7.4 and gassed continuously with a mixture of $95 \% \mathrm{O}_{2} / 5 \% \mathrm{CO}_{2}$. The strips were allowed to equilibrate for at least $1 \mathrm{~h}$ prior to the addition of oxytocin. The Krebs-Henseleit solution was changed every 15 min during the equilibration period. Following equilibration, contractions were stimulated by the addition of the uterotonic agent oxytocin to achieve a tissue bath concentration of $0.5 \mathrm{nM}$ for a period of $30 \mathrm{~min}$. Pre-incubation was then performed for a further $30 \mathrm{~min}$ with the following compounds: SR 144528 (a selective CB2 receptor antagonist), AM 251 (a selective CB1 receptor antagonist), methylene blue (a guanylate cyclase inhibitor), and iberiotoxin (IbTX, a BK $\mathrm{Ca}$ channel antagonist). The final bath concentration of SR 144528, AM 251, and methylene blue was $1 \mu \mathrm{M}$, while that of iberiotoxin was $100 \mathrm{nM}$ in accordance with previously published data (Dennedy et al. 2001, Houlihan et al. 2002, Bonz et al. 2003, Doheny et al. 2003). This was followed by the addition of abn-cbd in a cumulative manner at bath concentrations of $1 \mathrm{nM}, 10 \mathrm{nM}, 100 \mathrm{nM}, 1 \mu \mathrm{M}$, and $10 \mu \mathrm{M}$ (i.e. $10^{-9}-10^{-5} \mathrm{M}$ ) at 20-min intervals. Control experiments that tested for tachyphylaxis, with a single dose for a similar time period, revealed no difference between isolated exposure and cumulative exposure during this time.

Measurement of the contractile activity was performed by calculation of the integral of the selected area using the PowerLab hardware unit and Chart v3.6 software (AD Instruments, Oxfordshire, UK). The integrated tension for the 20-min period prior to the addition of the compound abn-cbd was calculated, and this value served as a control value because no significant reduction in myometrial contractility was observed in control strips over the duration of the experiment. The effects of cumulative doses of abn-cbd in the 
presence and absence of the various antagonists outlined above were then assessed by calculating the integral of contractile activity for 20 min following the administration of each drug concentration and by expressing these values as a percentage of the integrated contractile activity prior to any drug addition (i.e. percentage contractility).

\section{Drugs and solutions}

Stock solutions of oxytocin (Sigma-Aldrich) (1 mM), AM 251 (Tocris, Bristol, UK) (10 mM), and abn-cbd (Tocris) (1 mM) were prepared in ethanol. A stock solution of methylene blue (Sigma-Aldrich) $(10 \mathrm{mM})$ and IbTX $(10 \mu \mathrm{M}$; Tocris) was prepared using physiological saline $(0.9 \% \mathrm{NaCl})$. The compound SR 144528 was donated by Sanofi Recherche, Montpellier, France. A stock solution $(1 \mathrm{mM})$ was prepared using $0.9 \% \mathrm{NaCl}$. Serial dilutions of each drug were prepared daily as appropriate, and were maintained at room temperature. Fresh Krebs-Henseleit physiological salt solution was prepared daily.

\section{Statistical analysis}

Using the calculated integrals of contractile activity at each bath concentration, dose-response curves were analyzed by fitting the logistic equation: $Y=Y_{\max } \times D_{\mathrm{H}}^{\mathrm{n}} / \mathrm{EC}_{50}+D_{\mathrm{H}}^{\mathrm{n}}$, where $Y$ is the response (percentage contractility), $Y_{\max }$ is the maximal relaxation achieved, $D$ is the dose of agonist (abn-cbd), $\stackrel{n}{H}$ is the slope function, and $\mathrm{EC}_{50}$ is the agonist dose giving the half maximal response. Curve fitting was performed with the software package Prism (Graphpad Software, San Diego, CA, USA). For multiple comparisons, an ANOVA test was used, and post hoc comparisons were carried out using Fisher's LSD (protected $t$-test) test to compare $\mathrm{pD}_{2}\left(-\log \mathrm{EC}_{50}\right)$ values and MMI response values between two groups. The statistical package GBSTAT version 6.5 was used for statistical calculations. A Pvalue $<0.05$ was accepted as statistically significant.

\section{Declaration of interest}

The authors declare that there is no conflict of interest that could be perceived as prejudicing the impartiality of the research reported.

\section{Funding}

This research did not receive any specific grant from any funding agency in the public, commercial, or not-for-profit sector.

\section{References}

Begg M, Mo FM, Offertaler L, Bátkai S, Pacher P, Razdan RK, Lovinger DM \& Kunos G 2003 G protein-coupled endothelial receptor for atypical cannabinoid ligands modulates a $\mathrm{Ca}^{2+}$-dependant $\mathrm{K}^{+}$current. Journal of Biological Chemistry 278 46188-46194.

Berdyshev EV 2000 Cannabinoid receptors and the regulation of the immune response. Chemistry and Physics of Lipids 108 169-190.
Bonz A, Laser M, Kullmer S, Kniesch S, Babin-Ebell J, Popp V, Ertl G \& Wagner JA 2003 Cannabinoids acting on CB1 receptors decrease contractile performance in human atrial muscle. Journal of Cardiovascular Pharmacology 41 657-664.

Buscher U, Chen FC, Riesenkampff E, von Dehn D, David M \& Dudenhausen JW 2001 Effects of oxytocin receptor antagonist atosiban on pregnant myometrium in vitro. Obstetrics and Gynecology 98 117-121.

Dennedy MC, Friel AM, Gardeil F \& Morrison JJ 2001 Beta-3 versus beta-2 adrenergic agonists and preterm labour: in vitro uterine relaxation effects. British Journal of Obstetrics and Gynaecology 108 605-609.

Dennedy MC, Friel AM, Houlihan DD, Broderick VM, Smith T \& Morrison JJ 2004 Cannabinoids and the human uterus during pregnancy. American Journal of Obstetrics and Gynaecology 190 2-9.

Devane WA, Hanus L, Breuer A, Pertwee RG, Stevenson LA, Griffin G, Gibson D, Mandelbaum A, Etinger A \& Mechoulam R 1992 Isolation and structure of a brain constituent that binds to the cannabinoid receptor. Science 258 1946-1949.

Doheny HC, Houlihan DD, Ravikumar N, Smith TJ \& Morrison JJ 2003 Human chorionic gonadotrophin relaxation of human pregnant myometrium and activation of the $\mathrm{BK}_{\mathrm{Ca}}$ channel. Journal of Clinical Endocrinology and Metabolism 88 4310-4315.

Gebremedhin D, Lange AR, Campbell WB, Hillard CJ \& Harder DR 1999 Cannabinoid CB1 receptor of cat cerebral arterial muscle functions to inhibit L-type $\mathrm{Ca}^{2+}$ channel current. American Journal of Physiology $2762085-2093$.

Habayeb OM, Taylor AH, Evans MD, Cooke MS, Taylor DJ, Bell SC \& Konje JC 2004 Plasma levels of the endocannabinoid anandamide in women - a potential role in pregnancy maintenance and labor? Journal of Clinical Endocrinology and Metabolism 89 5482-5487.

Hillard CJ 2000 Endocannabinoids and vascular function. Journal of Pharmacology and Experimental Therapeutics 294 27-32.

Hinds NM, Ullrich K \& Smid SD 2006 Cannabinoid 1 (CB1) receptors coupled to cholinergic motor neurons inhibit neurogenic circular muscle contractility in the human colon. British Journal of Pharmacology 148 191-199.

Houlihan DD, Dennedy MC \& Morrison JJ 2002 Polyamine effects on human myometrial contractility. American Journal of Obstetrics and Gynaecology 186 778-783.

Howlett AC 2002 The cannabinoid receptors. Prostaglandins \& Other Lipid Mediators 68 619-631.

Ishac EJ, Jiang L, Lake KD, Varga K, Abood ME \& Kunos G 1996 Inhibition of exocytotic noradrenaline release by presynaptic cannabinoid CB1 receptors on peripheral sympathetic nerves. British Journal of Pharmacology 118 2023-2028.

Jarai Z, Wagner JA, Varga K, Lake KD, Compton DR, Martin BR, Zimmer AM, Bonner TI, Buckley NE, Mezey $\mathrm{E}$ et al. 1999 Cannabinoid-induced mesenteric vasodilation through an endothelial site distinct from CB1 or CB2 receptors. PNAS 96 14136-14141.

Khan RN, Smith SK, Morrison JJ \& Ashford ML $1997 \mathrm{Ca}^{2+}$ dependence and pharmacology of large-conductance $\mathrm{K}^{+}$channels in nonlabor and labor human uterine myocytes. American Journal of Physiology 273 1721-1731.

Levitan IB 1994 Modulation of ion channels by protein phosphorylation and dephosphorylation. Annual Review of Physiology 56 193-212.

Luckas MJ \& Wray S 2000 A comparison of the contractile properties of human myometrium obtained from the upper and lower uterine segments. British Journal of Obstetrics and Gynaecology 107 1309-1311.

Martin RS, Luong LA, Welsh NJ, Eglen RM, Martin GR \& MacLennan SJ 2000 Effects of cannabinoid receptor agonists on neuronally-evoked contractions of urinary bladder tissues isolated from rat, mouse, pig, donkey and human. British Journal of Pharmacology 129 1707-1715.

Matsuda LA, Lolait SJ, Brownstein MJ, Young AC \& Bonner TI 1990 Structure of a cannabinoid receptor and functional expression of the cloned cDNA. Nature 346 561-564.

Modzelewska B \& Kostrzewska A 2005 The influence of methylene blue on the spontaneous contractility of the non-pregnant human myometrium and on the myometrial response to DEA/NO. Cellular and Molecular Biology Letters 10 389-400. 
Offertaler L, Mo FM, Batkai S, Liu J, Begg M, Razdan RK, Martin BR, Bukoski RD \& Kunos G 2003 Selective ligands and cellular effectors of a G protein-coupled endothelial cannabinoid receptor. Molecular Pharmacology 63 699-705.

Park B, McPartland JM \& Glass M 2004 Cannabis, cannabinoids and reproduction. Prostaglandins, Leukotrienes, and Essential Fatty Acids $\mathbf{7 0}$ 189-197.

Pertwee RG 2001 Cannabinoids and the gastrointestinal tract. Gut 48 859-867.

Slattery MM, Friel AM, Healy DG \& Morrison JJ 2001 Uterine relaxant effects of cyclooxygenase-2 inhibitors in vitro. Obstetrics and Gynecology 98 563-569.

Wang H, Xie H \& Dey SK 2008 Loss of cannabinoid receptor CB1 induces preterm birth. PLOS ONE 3 e3320.

Wilson RI \& Nicoll RA 2002 Endocannabinoid signalling in the brain. Science 296 678-682.
Zhou XB, Wang GX, Ruth P, Huneke B \& Korth M 2000 BK(Ca) channel activation by membrane-associated cGMP kinase may contribute to uterine quiescence in pregnancy. American Journal of Physiology. Cell Physiology 279 1751-1759.

Zygmunt PM, Petersson J, Andersson DA, Chuang $H$, Sørgård $M$, Di Marzo V, Julius D \& Högestätt ED 1999 Vanilliod receptors on sensory nerves mediate the vasodilator action of anandamide. Nature 400 452-457.

Received 6 November 2009

First decision 2 December 2009

Revised manuscript received 3 January 2010

Accepted 12 January 2010 